\title{
Short-Term Landfill Methane Emissions Dependency on Wind
}

\author{
Madjid Delkash ${ }^{\mathrm{a}}$, Bowen Zhou ${ }^{\mathrm{b}}$, Byunghyun Han ${ }^{\mathrm{a}}$, Fotini K. Chow ${ }^{\mathrm{b}}$, Chris W. Rella ${ }^{\mathrm{c}}$, Paul T. Imhoffa*
}

aDepartment of Civil and Environmental Engineering, University of Delaware, Newark, DE 19716

bDepartment of Civil and Environmental Engineering, University of California, Berkeley, CA 94720-1710

'Picarro, Inc., 3105 Patrick Henry Dr. Santa Clara, CA 95054

\section{Abstract}

Short-term (2-10 h) variations of whole-landfill methane emissions have been observed in recent field studies using the tracer dilution method for emissions measurement. To investigate the cause of these variations, the tracer dilution method is applied using 1-min emissions measurements at Sandtown Landfill (Delaware, USA) for a 2-h measurement period. An atmospheric dispersion model is developed for this field test site, which is the first application of such modeling to evaluate atmospheric effects on gas plume transport from landfills. The model is used to examine three possible causes of observed temporal emissions variability: temporal variability of surface wind speed affecting whole landfill emissions, spatial variability of emissions due to local wind speed variations, and misaligned tracer gas release and methane emissions locations. At this site, atmospheric modeling indicates that variation in tracer dilution method emissions measurements may be caused by whole-landfill emissions variation with wind speed. Field data collected over the time period of the atmospheric model simulations corroborate this result: methane emissions are correlated with wind speed on the landfill surface with $R^{2}=0.51$ for data $2.5 \mathrm{~m}$ above ground, or $R^{2}=0.55$ using data $85 \mathrm{~m}$ above ground, with emissions increasing by up to a factor of 2 for an approximately 30\% increase in wind speed. Although the atmospheric modeling and field test are conducted at a single landfill, the results suggest that wind-induced emissions may affect tracer dilution method emissions measurements at other landfills.

*Corresponding author

Email addresses: delkash@udel.edu (Madjid Delkash), zhoubowen58@gmail.com (Bowen Zhou), gragebhan@gmail.com (Byunghyun Han), imhoff@udel.edu (Paul T. Imhoff), tinakc@ berkeley.edu (Fotini K. Chow), rella@picarro.com (Chris W. Rella) 
29 Keywords:

30 Landfill, Methane emissions, Tracer dilution method, Atmospheric modeling, Wind-dependent emissions 31

32

33 


\section{Introduction}

Methane $\left(\mathrm{CH}_{4}\right)$ from biological decomposition of buried waste in landfills is considered an important source of anthropogenic $\mathrm{CH}_{4}$ emissions (Scheehle et al., 2006). Measurement of $\mathrm{CH}_{4}$ emissions is useful for evaluating landfill gas control measures and improving estimates of $\mathrm{CH}_{4}$ emissions for greenhouse gas inventories. $\mathrm{CH}_{4}$ emissions from landfills are not constant, with annual changes associated with aging of waste (Foster-Wittig et al., 2015) or changes in the composition of landfilled materials (Weitz et al., 2002; Allen et al., 1997), and seasonal variations due to changes in temperature and moisture content of cover soils that affect gas transport and methane oxidation (Wang et al., 2011; Chanton and Liptay 2000; Stern et al., 2007).

Short-term emissions variations due to weather have also been reported. Czepiel et al. (2003) measured whole-landfill $\mathrm{CH}_{4}$ emissions using the tracer dilution method (TDM) and found

$45 \mathrm{CH}_{4}$ emissions increased by a factor of five when barometric pressure dropped approximately 15 mbar over a 1-month period of emissions measurements. Xu et al. (2014) measured $\mathrm{CH}_{4}$ emissions

47 from portions of landfill cells using the eddy covariance method and attributed a 35-fold variation in emissions to barometric pressure variations. emissions (McBain et al., 2005; Rachor et al., 2013) - as wind speed increases, gas pressures

51 fluctuate because of atmospheric turbulence at the landfill surface causing a pumping effect that

52 increases emissions. Numerical modeling of gas transport processes in landfill cover soils suggests

53 that pressure pumping caused by wind turbulence may increase $\mathrm{CH}_{4}$ emissions up to four times 54 that of the $\mathrm{CH}_{4}$ diffusive flux for some soil conditions (Poulsen and Moldrup, 2006). While the

Nomenclature: Tracer Dilution Method (TDM), cavity ring-down spectroscopy (CRDS), Advanced Regional Prediction System (ARPS), Constant Flux 1 (CF1), Constant Flux 2 (CF2), Variable Flux 1 (VF1) and Variable Flux 2 (VF2), Three point flux (3Pts), above ground level (AGL). 
55 effect of wind speed on $\mathrm{CH}_{4}$ emissions has been observed in flux chamber (Rachor et al., 2013)

56 and eddy covariance (McBain et al., 2005) measurements over portions of a landfill surface, there

57 are no data indicating variations in whole-landfill $\mathrm{CH}_{4}$ emissions because of wind speed.

58 TDM, also known as the tracer correlation or dynamic plume technique, was developed to 59 quantify whole-landfill $\mathrm{CH}_{4}$ emissions and has seen increased use in the past several years because 60 of improved gas measurement technology (Foster-Wittig et al., 2015; Mønster et al., 2015; 61 Mønster et al., 2014). A tracer gas, traditionally sulfur hexafluoride $\left(\mathrm{SF}_{6}\right)$ or nitrous oxide $\left(\mathrm{N}_{2} \mathrm{O}\right)$ 62 but more recently acetylene $\left(\mathrm{C}_{2} \mathrm{H}_{2}\right)$, is released at a known rate at multiple locations on the landfill 63 which then mixes with $\mathrm{CH}_{4}$ emissions from the landfill surface (Czepiel et al., 2003; Galle et al., 64 2001). Downwind of the source if the released tracer gas is sufficiently well mixed with emitted $65 \mathrm{CH}_{4}$, the mass flux of $\mathrm{CH}_{4}$ is calculated from the known mass flux of the tracer gas multiplied by 66 the ratio of the $\mathrm{CH}_{4}$ to tracer gas concentration

$67 \quad E_{C_{4}}=E_{T} \frac{M_{C H_{4}}}{M_{T}} \frac{C_{C H_{4}}}{C_{T}}$

68 where $E_{\mathrm{CH}_{4}}$ and $E_{T}$ are $\mathrm{CH}_{4}$ and tracer emissions rates, respectively, expressed as mass flowrate $69(\mathrm{~kg} / \mathrm{min}) ; M_{C_{4}}$ and $M_{T}$ are the molecular weights of $\mathrm{CH}_{4}$ and tracer; and $C_{C H_{4}}$ and $C_{T}$ are the 70 concentrations of $\mathrm{CH}_{4}$ and tracer above background (ppm). If measured at a fixed location, this 71 concentration ratio can be averaged over time by regressing scatter plots of $C_{C_{H_{4}}}$ versus $C_{T}$ to 72 obtain the fitted slope used for the ratio $C_{C_{4}} / C_{T}$ in equation (1) (Galle et al., 2001; Börjesson et 73 al., 2009). When measured by a moving vehicle that traverses the downwind gas plumes, similar 74 scatter plots can be generated (Foster-Wittig et al., 2015; Mønster et al., 2014), or, more 75 commonly, $C_{\mathrm{CH}_{4}}$ and $C_{T}$ are integrated individually in space and the ratio of the two integrations 76 are used to represent the ratio $C_{C_{4}} / C_{T}$ (Foster-Wittig et al., 2015; Mønster et al., 2014). 
With increasing TDM applications, significant variations in measured $\mathrm{CH}_{4}$ emissions have

78 been reported for short measurement campaigns. For example, during measurement campaigns

79 that ranged from 1.7 to $4.3 \mathrm{~h}$, Scheutz et al. (2011) reported a coefficient of variation of $\mathrm{CH}_{4}$ 80 emissions up to 0.30. Similarly, in a recent study of nine Danish landfills where single 81 measurement campaigns ( 2 to $10 \mathrm{~h}$ duration) were conducted at each landfill, the average 82 coefficient of variation was 0.19 for the nine landfills with a maximum of 0.35 (Mønster et al., 83 2015). On the other hand, when the TDM method was tested with controlled releases of $\mathrm{CH}_{4}$ and 84 tracer (Mønster et al., 2014), the coefficient of variation was much smaller: for three tracer/ $\mathrm{CH}_{4}$ 85 release configurations and measurements at three downwind transects, the mean coefficient of 86 variation was 0.05 with maximum of 0.15 , which occurred for the configuration with significant 87 misalignment between $\mathrm{CH}_{4}$ and tracer and for measurements close to the points of gas release. 88 The cause of the increased coefficient of variation for landfill $\mathrm{CH}_{4}$ emissions versus controlled $89 \mathrm{CH}_{4}$ releases is unclear: it may be due to misalignment of tracer release and regions of $\mathrm{CH}_{4}$ emissions, short-term variations in emissions possibly due to wind, or other factors.

The primary objective of this work is to determine if short-term variations in whole-landfill

$92 \mathrm{CH}_{4}$ emissions measured with TDM might be due to variations in wind speed. If wind affects 93 whole-landfill $\mathrm{CH}_{4}$ emissions, in some situations TDM may result in biased estimates of emissions, 94 since TDM requires sufficient wind speed to generate well-mixed gas plumes downwind of the 95 landfill (Foster-Wittig et al., 2015), and thus measurements are not possible under low wind speeds 96 (Foster-Wittig et al., 2015; Galle et al., 2001). A secondary objective is to evaluate the utility of 97 atmospheric dispersion modeling to understand the influence of atmospheric conditions on landfill 98 emissions measurements requiring sampling of landfill gas plumes. 
To accomplish these objectives, $\mathrm{CH}_{4}$ emissions data were collected using TDM from the

100

101

102

103

104

105

106

107

108

109

110

111

112

113

114

115

116

117

118

119

120

121

Sandtown Landfill in Delaware (USA) for a short-term experiment in March 2010. Correlations

between wind conditions on the landfill surface and $\mathrm{CH}_{4}$ emissions were explored with field data.

An atmospheric dispersion model was developed for the site and used for three purposes: to determine the travel time of emissions from the landfill surface to a downwind measurement location; to refine data filtering techniques for TDM, since in the atmospheric model $\mathrm{CH}_{4}$ emissions were known and could be compared with TDM results from analysis of model output; and to assess if temporal variation in emissions determined from TDM might be caused by misalignment of tracer/ $\mathrm{CH}_{4}$ emissions locations or wind conditions. Field data and numerical model results were collected at one downwind location at two measurement heights, at the ground surface and at approximately $85 \mathrm{~m}$ above ground to evaluate the benefit of above ground measurements on TDM.

\section{Materials and methods}

\subsection{Site description}

The Sandtown Landfill has an active landfill gas collection system in all landfill cells and ongoing waste disposal activities. Area A-B $\left(110,000 \mathrm{~m}^{2}\right)$ in Figure 1 was filled with 532,000 tons of household waste from 1980 to 1988 and is now closed and equipped with a final cover. A total of 1,226,000 tons of waste were landfilled in Area C and D (170,000 $\left.\mathrm{m}^{2}\right)$ from 1988 to 1998 and these regions have intermediate covers. Area $\mathrm{E}\left(132,000 \mathrm{~m}^{2}\right)$ is an active cell where 2 million tons of waste have been landfilled since 1999: portions of Area E have intermediate and daily cover soils. The landfill rises $40 \mathrm{~m}$ above the surrounding topography and is located in a coastal plain with minimal variations in ground elevation for a $100 \mathrm{~km}$ radius surrounding the site. The landfill 
122 is in a rural area with low traffic density and is surrounded by farms with 25 to $30 \mathrm{~m}$ high pine 123 trees.

124 Figure 1

\section{$125 \quad 2.2$ Field emissions measurements}

TDM was utilized to quantify $\mathrm{CH}_{4}$ emissions from the Sandtown Landfill. Details of the

127 method are found elsewhere (Czepiel et al., 2003; Foster-Wittig et al., 2015; Mønster et al., 2015).

128 In this application, $\mathrm{C}_{2} \mathrm{H}_{2}$ was selected as the tracer gas (Foster-Wittig et al., 2015; Mønster et al., 129 2014). Three $\mathrm{C}_{2} \mathrm{H}_{2}$ gas cylinders were located on the upstream edge of the active landfill region 130 on Area E (Figure 1), identified as the main $\mathrm{CH}_{4}$ source during preliminary ground-level 131 atmospheric $\mathrm{CH}_{4}$ measurements around the landfill in March 2010. The gas cylinders were 132 arranged $70 \mathrm{~m}$ apart in a line perpendicular to the mean wind direction. Mass flow controllers were used to discharge $\mathrm{C}_{2} \mathrm{H}_{2}$ at a constant mass flow rate of $E_{C_{2} H_{2}}=52.23 \mathrm{~g} \mathrm{C}_{2} \mathrm{H}_{2} / \mathrm{min}$.

$C_{C_{4}}$ and $C_{C_{2} H_{2}}$ measurements for the TDM are often obtained by making transects of the 135 downwind gas plumes perpendicular to the mean wind direction with a vehicle-mounted gas 136 sampling system (Czepiel et al., 2003; Börjesson et al., 2009). Downwind roadways are not, 137 however, always located with suitable alignment for TDM measurements. For these situations, if 138 plume meandering is adequate to cause plumes to move into and out of a fixed measurement 139 location, stationary measurements may be used and have provided similar estimates of $\mathrm{CH}_{4}$ 140 emissions (Green et al., 2010). Here, all measurements were conducted at one geographic location, 141 indicated in Figure 1, since road alignment was not ideal for vehicle-mounted gas sampling with 142 the prevailing wind. Sampling along downwind roads was attempted but resulted in poor data: 143 tracer and $\mathrm{CH}_{4}$ plumes were either not well mixed or gas concentrations were too low for accurate 144 measurements. 
A prototype gas analyzer developed by Picarro, Inc. (Sunnyvale, CA) and based on an all-

147 optical technique called cavity ring-down spectroscopy (CRDS) was used to measure $C_{\mathrm{CH}_{4}}$ and $148 C_{C_{2} H_{2}}$ (Crosson, 2008). The CRDS analyzer measures $\mathrm{CH}_{4}$ and $\mathrm{C}_{2} \mathrm{H}_{2}$ in less than 2 s with a 149 measurement precision (one estimated standard error) of $0.8 \mathrm{ppb}$ and $0.2 \mathrm{ppb}$ for $\mathrm{CH}_{4}$ and $\mathrm{C}_{2} \mathrm{H}_{2}$, 150 respectively, and has been used in other recent TDM measurements at landfills (Foster-Wittig et 151 al., 2015; Mønster et al., 2015). Instrument calibration is discussed in Supporting Information. The TDM was used to measure $\mathrm{CH}_{4}$ emissions using data collected at 2.5 and $85 \mathrm{~m}$ above 153 ground level (AGL) at the same location $\left(39^{\circ} 01^{\prime} 45^{\prime \prime} \mathrm{N}, 74^{\circ}, 42^{\prime} 47^{\prime \prime} \mathrm{W}\right)$ between 14:00 to 16:00 154 local time on March 6, 2010. A single stationary location was used since a large, open region was 155 needed to launch and monitor the weather balloon used for measurements at $85 \mathrm{~m}$, and a limited 156 number of locations were available in the actively farmed land surrounding the landfill. A short 157 measurement period was selected since changes in landfill operations or in soil temperature and 158 barometric pressure, which are known to affect $\mathrm{CH}_{4}$ emission, would be minor, permitting an 159 examination of wind on emission. For $85 \mathrm{~m}$ measurements, a chloroprene weather balloon $(2.4 \mathrm{~m}$ 160 diameter) was inflated with helium and flown while tethered using light-weight nylon rope. Teflon 161 tubing (1/8" ID, 3/16" OD, and $150 \mathrm{~m}$ long) was attached to the balloon and connected to a vacuum 162 pump, which when operated resulted in a $22 \mathrm{~s}$ residence time of the air in the tubing. The balloon 163 height was measured by the nearly vertical tubing length and ranged from 70 to $100 \mathrm{~m}$, with an 164 average height of approximately $85 \mathrm{~m}$. By connecting and disconnecting the Teflon tubing to the 165 gas analyzer alternatively every 4 to 9 minutes, measurements of $C_{C_{H_{4}}}$ and $C_{C_{2} \mathrm{H}_{2}}$ could be made at $1662.5 \mathrm{~m}$ AGL or $85 \mathrm{~m}$ AGL at the flying weather balloon. 
168 Young's 0513, Campbell Scientific) $2 \mathrm{~m}$ AGL on top of Area E, which is $40 \mathrm{~m}$ higher than

169 surrounding terrain (see Figure 1), and with a weather station at the base of the landfill. One-

170 minute averaged wind speed data were recorded by the wind monitor. Average temperature and

171 barometric pressure during measurements at the landfill base were $8{ }^{\circ} \mathrm{C}$ and $101.3 \mathrm{kPa}$,

172 respectively.

\section{$173 \quad 2.3$ Atmospheric dispersion modeling}

Given the variability in $\mathrm{CH}_{4}$ emissions discussed below, relationships between landfill 175 operations, atmospheric conditions, and $\mathrm{CH}_{4}$ emissions were explored. We postulated that 176 downwind $\mathrm{CH}_{4}$ and tracer concentrations obtained from ground and airborne measurements could

177 be used to quantify temporal $\mathrm{CH}_{4}$ emissions variations. To test this, an atmospheric dispersion 178 model was developed that described wind conditions in the vicinity of the landfill for the $2 \mathrm{~h}$ TDM 179 test. Controlled releases of $\mathrm{CH}_{4}$ and tracer were made at different locations in the model landfill, 180 and then forward simulations performed to predict downwind gas concentrations at 2.5 and $85 \mathrm{~m}$ AGL at the field measurement location shown in Figure 1. Simulations were performed to test 182 three hypotheses about TDM-measured whole landfill $\mathrm{CH}_{4}$ emissions: TDM emissions measurements will be correlated with wind speed if (1) local $\mathrm{CH}_{4}$ emissions vary with wind speed 184 causing wind-induced variations of whole landfill emissions, (2) if the spatial distribution of $\mathrm{CH}_{4}$ 185 emissions varies with wind speed but whole landfill emissions are constant, and (3) if local $\mathrm{CH}_{4}$ 186 emissions are constant but significantly misaligned with tracer emissions locations. In the process 187 of testing these hypotheses, the atmospheric dispersion model was also used to develop data 188 filtering techniques that were then applied to field measurements. 
190

developed at the Center for Analysis and Prediction of Storms at the University of Oklahoma. It is a non-hydrostatic meso-scale and small-scale finite-difference numerical weather prediction model that runs in parallel using the message passing interface. Descriptions of the model can be found in Xue et al. (2000) with relevant details presented in Supporting Information and summarized below.

Daytime atmospheric flow was simulated using ARPS for $3 \mathrm{~h}$ starting from 13:00 to 16:00 local time on March 6, 2010. Results from the last $2 \mathrm{~h}$ period were used for analysis. To resolve the local flow around the landfill, a multi-scale approach was adopted. Simulations were first performed on a $200 \times 200 \mathrm{~km}^{2}$ area with $2400 \mathrm{~m}$ horizontal resolution which covered the entire Delmarva Peninsula. Realistic initial and lateral boundary conditions were obtained from meteorological analysis data produced by the North American Mesoscale forecast system. Results from the $2400 \mathrm{~m}$ grid were used to drive lateral boundaries of a $150 \mathrm{~m}$ grid, which was then fed into a $30 \mathrm{~m}$ grid. Vertical grid stretching was applied to better resolve the surface layer. On the finest grid, the vertical resolution was $20 \mathrm{~m}$ with $5 \mathrm{~m}$ spacing near the surface. The land surface was represented with high resolution terrain $(10 \mathrm{~m})$ and land cover $(30 \mathrm{~m})$ data from the Delaware Solid Waste Authority and the U.S. Geological Survey (see Figure S1 in Supporting Information). Nested model parameters are listed in Table S1 in Supporting Information.

On the $2400 \mathrm{~m}$ grid, ARPS was run in meso-scale mode with boundary layer parameterizations (Sun and Chang, 1986) to model the synoptic-scale flows. On the inner (150 m and $30 \mathrm{~m}$ ) grids, large-eddy simulations were performed to resolve turbulent flows in the atmospheric boundary layer, details of which are described in Supporting Information. On the 30 m grid a numerical tracer, representing $\mathrm{CH}_{4}$ or $\mathrm{C}_{2} \mathrm{H}_{2}$, was released at constant or variable mass 
212 flow rate, depending on the simulation, on top of the landfill from 1400 LST onwards. Tracers

213 were released from the three tracer release points shown in Figure 1 that correspond to the location

214 of field tracer release points, or from 100 points or 89 points distributed in a spatially uniform grid

215 covering Area C or Area D, respectively, as shown in Figure 1. A vertical column of model results

216 at the field sampling location was recorded every $2 \mathrm{~s}$, while 3D flow fields were output every

217 minute. Wind velocity was also output every $2 \mathrm{~s}$ at $2.5 \mathrm{~m}$ AGL for selected locations.

218 Due to the fine vertical grid spacing with near surface grid-stretching, the $30 \mathrm{~m}$ pine trees

219 surrounding the landfill were represented by 7 grid points in the vertical direction. The traditional

220 representation of trees in mesoscale atmospheric models with an elevated roughness length $\left(z_{o} \sim\right.$

$2211 \mathrm{~m}$ ) was insufficient for the large-eddy simulation domain. Therefore a canopy model was adopted

222 to explicitly resolve the additional drag on the atmospheric flow by the trees, which is described

223 in Supporting Information.

224 The increased turbulence within the canopy layer led to more mixing of the tracer, and 225 resulted in low, broad peaks near the surface. In general, the canopy model acted like a semi226 permeable flow obstacle. An internal boundary layer formed downwind of the canopy, so that wind 227 speed reduction was also felt above the canopy height. At the $85 \mathrm{~m}$ balloon height, mean wind 228 speed was reduced by $\sim 10 \%$ when the canopy model was on.

229 Four different numerical tracer release configurations were considered. Three Point (3Pts) 230 simulation mimicked $\mathrm{C}_{2} \mathrm{H}_{2}$ release in the field tests and is described by

$$
Q_{3 P t s}\left(\vec{x}_{i}, t\right)=\frac{Q}{3} ; i=1: 3
$$

232 where $Q$ is the total tracer mass flux that is invariant with time. The three release points $\left(\vec{x}_{i}\right)$ were 233 in close proximity to the $\mathrm{C}_{2} \mathrm{H}_{2}$ release points for the field tests shown in Figure 1. For the Constant 234 Flux 1 (CF1), Variable Flux 1 (VF1), and Variable Flux 2 (VF2) simulations, the numerical tracer 
235 was released from 100 uniformly spaced grid points in Area C in Figure 1. For the Constant Flux

2362 (CF2) simulation, the numerical tracer was released from 89 uniformly spaced grid points in

237 Area D in Figure 1.The tracer releases for CF1 and CF2 are described by

238

239

$$
\begin{gathered}
Q_{C F}\left(\vec{x}_{i}, t\right)=\frac{Q}{100} ; i=1: 100 \\
Q_{C F 2}\left(\vec{x}_{i}, t\right)=\frac{0.89 Q}{89} ; i=1: 89
\end{gathered}
$$

where $Q_{C F 1}\left(\vec{x}_{i}, t\right)$ and $Q_{C F 2}\left(\vec{x}_{i}, t\right)$ are the tracer mass fluxes at location $\vec{x}_{i}$ and are equal to the total

241

242

243

244

245

246 mass flux divided by the 100 or 89 release points in Area $\mathrm{C}$ and $\mathrm{D}$, respectively. Because identically sized surface grid cells were used for $\mathrm{CH}_{4}$ emissions in $\mathrm{CF} 1$ and $\mathrm{CF} 2$ while Area D was approximately $89 \%$ of Area $\mathrm{C}$, the number of release points was larger for $\mathrm{CF} 1$ than $\mathrm{CF} 2$. $\mathrm{CF} 1$ and $\mathrm{CF} 2$ simulations were used to represent either a uniform, time-invariant release of $\mathrm{CH}_{4}$, or release of a tracer gas in perfect alignment with the $\mathrm{CH}_{4}$ release (CF1 simulation) in simulations VF1 and VF2, where $\mathrm{CH}_{4}$ emissions varied with wind conditions.

The numerical tracer released in simulations VF1 and VF2 was dependent on wind speed

$$
V\left(\vec{x}_{i}, t\right)=\sqrt{u\left(\vec{x}_{i}, t\right)^{2}+v\left(\vec{x}_{i}, t\right)^{2}+w\left(\vec{x}_{i}, t\right)^{2}} ; i=1: 100
$$

where $(u, v, w)$ are magnitudes of wind velocity in $x, y$ and $z$ directions at $2.5 \mathrm{~m}$ AGL. Tracer release for VF1 is described by

$$
Q_{V F 1}\left(\vec{x}_{i}, t\right)=\frac{V\left(\vec{x}_{i}, t\right)}{\sum_{j=1}^{100} V\left(\vec{x}_{j}, t\right)} Q ; i=1: 100
$$

where $Q_{V F 1}\left(\vec{x}_{i}, t\right)$ is the tracer mass flux at location $\vec{x}_{i}$ and is equal to the total mass flux $Q$ normalized by the relative wind speed at this measurement location. The summation of $Q_{V F 1}$ over all $\vec{x}_{i}$ is the total $\mathrm{CH}_{4}$ flux from Area $\mathrm{C}$ and was invariant with time but varied spatially at each time step depending on local wind speed.

The numerical tracer release in simulation VF2 is described by 


$$
Q_{V F 2}\left(\vec{x}_{i}, t\right)=\frac{\sum_{j=1}^{100} V\left(\vec{x}_{j}, t\right)}{\frac{\sum_{k=1}^{n}\left(\sum_{j=1}^{100} V\left(\vec{x}_{j}, t_{k}\right)\right)}{n}}\left(\frac{Q}{100}\right) ; i=1: 100
$$

258 where $Q_{V F 2}\left(\vec{x}_{i}, t\right)$ is the tracer mass flux at location $\vec{x}_{i}$ and is equal to the total mass flux $Q$

259 normalized by the average relative wind speed in Area C. Here, $n$ is the number of simulation time 260 steps. $Q_{V F 2}$ represents $\mathrm{CH}_{4}$ emission that is spatially uniform within Area $\mathrm{C}$ but varies linearly 261 with the average Area C wind speed.

To test the three hypotheses described above, correlations between TDM-measured $\mathrm{CH}_{4}$ 263 emissions and wind conditions on the landfill surface were examined using simulation results. To 264 account for the travel time for gases emitted from the landfill to the downwind measurement

265 location (see Figure 1), estimates of travel time are necessary to adjust wind speeds at the landfill 266 surface to the corresponding time of TDM-measured $\mathrm{CH}_{4}$ emissions. The numerical technique of 267 Deleersnijder et al. (2001) was applied to estimate the travel time $T$ of numerical tracer gas to the 268 downwind measurement location and details are in Supporting Information.

\section{Results and discussion}

\subsection{Field emissions measurements}

TDM data are typically integrated in space (Mønster et al., 2015; Foster-Wittig et al., 2015;

273 Mønster et al., 2014) or time (Börjesson et al., 2009; Galle et al., 2001) to estimate average $\mathrm{CH}_{4}$

274 emissions. To illustrate the variability in raw data from the field campaign, instantaneous emission

275 measurements determined using equation (1) are shown in Figure 2. Data alternate between 276 measurements at 2.5 and $85 \mathrm{~m} \mathrm{AGL}$, with time gaps between data sets for switching measurement 277 heights. When $\mathrm{CH}_{4}$ concentrations were at or below background, $\mathrm{CH}_{4}$ emissions were plotted as 278 zero, although this only indicates the $\mathrm{CH}_{4}$ plume did not intersect the measurement location at that 
279 time. Variability between individual $\mathrm{CH}_{4}$ emissions measurements was large and was not 280 correlated with changes in wind direction, which are shown in Figure 3. For example, there was 281 no significant change in wind direction from 15:15-16:00, while emissions variations during this 282 period are similar to those from 14:15-15:15 when wind direction did change. Average 283 measurements during some periods differed significantly: for example, mean $\mathrm{CH}_{4}$ emissions at 85 $284 \mathrm{~m}$ AGL between 14:24-14:26 was 45\% smaller than mean $\mathrm{CH}_{4}$ emissions between 14:57-14:60 285 and statistically different $(\mathrm{t}$-Test of means, $\mathrm{p}<0.001)$. When averaged over the entire measurement 286 period, though, emissions measurements at 2.5 and $85 \mathrm{~m}$ AGL were $2330 \pm 60 \mathrm{~g}$ and $2289 \pm 46 \mathrm{~g}$ $287 \mathrm{CH}_{4} / \mathrm{min}$ (+/- values represent $95 \%$ confidence interval), respectively. Thus, while field data 288 indicate temporal variability in $\mathrm{CH}_{4}$ emissions, mean measurements at the two sampling heights 289 for the entire 2-h sampling period were similar, differing by less than $2 \%$. Understanding the cause 290 of temporal variability in emissions is an objective of this work.

$291 \quad$ Figure 2

It is important to note that after subtracting background concentrations, $1.88 \mathrm{ppm}$ and 0.86 293 ppb for $C_{C_{4}}$ and $C_{C_{2} H_{2}}$, respectively, peak $C_{C_{4}}$ and $C_{C_{2} H_{2}}$ averaged over all 1-min measurement 294 periods were smaller at 2.5 than at $85 \mathrm{~m} \mathrm{AGL:} \overline{C_{C_{H}}}=258 \pm 45 \mathrm{ppb}$ and $\overline{C_{C_{2} \mathrm{H}_{2}}}=2.37 \pm 0.84$ $295 \mathrm{ppb}$ at $2.5 \mathrm{~m} \mathrm{AGL}$, but $\overline{C_{C_{4}}}=323 \pm 87 \mathrm{ppb}$ and $\overline{C_{C_{2} \mathrm{H}_{2}}}=3.59 \pm 99 \mathrm{ppb}$ at $85 \mathrm{~m}$ AGL. Higher 296 gas concentrations should result in more accurate emissions measurement, since the signal to noise 297 ratio is larger (Foster-Wittig et al., 2015). During some measurement periods at $2.5 \mathrm{~m}$ AGL, 298 increases in $C_{C_{2} H_{2}}$ occurred without corresponding increases in $C_{C_{4}}$, which we attributed to 299 ground-level sources of $\mathrm{C}_{2} \mathrm{H}_{2}$ like motor vehicles (see Figure S2). Higher gas concentrations and 300 the absence of unexplained increases in $C_{C_{2} \mathrm{H}_{2}}$ at $85 \mathrm{~m}$ AGL suggest that emissions measurements 301 may be more accurate at 85 than $2.5 \mathrm{~m}$ AGL. 


\subsection{Comparison of atmospheric dispersion model to field data}

Wind monitor data from the top of Sandtown Landfill and $\mathrm{C}_{2} \mathrm{H}_{2}$ concentration at the downwind sampling location (see Figure 1) were used to validate the atmospheric dispersion model. Wind speed and direction from field data and model simulations are shown in Figure 3 and show good agreement: model-predicted mean $(\overline{\bar{V}})$ and standard deviation $\left(s_{V}\right)$ of wind speed, and the resultant mean wind direction $\left(\bar{\theta}_{R V}\right)$ on the landfill surface were $\overline{\bar{V}}=4.5 \mathrm{~m} / \mathrm{sec} s_{V}=1 \mathrm{~m} / \mathrm{sec}$ and $\bar{\theta}_{R V}=320^{\mathrm{O}}$, respectively, compared to measured values of $\overline{\bar{V}}=5 \mathrm{~m} / \mathrm{sec} s_{V}=0.8 \mathrm{~m} / \mathrm{sec}$ and $\bar{\theta}_{R V}=320^{\circ}$, where the double overbar indicates a 2-h average of 1-min averaged wind speeds. Thus, without tuning or data assimilation the atmospheric model matched available wind data well.

Simulation 3Pts describes the release of $\mathrm{C}_{2} \mathrm{H}_{2}$ from three gas cylinders on the landfill surface. Normalized tracer concentrations $\left(C_{N}=\left(C-C_{\min }\right) /\left(C_{\max }-C_{\min }\right)\right)$ at 2.5 and $85 \mathrm{~m}$ AGL for simulation 3Pts and field measurements are displayed in Figure 4. While the match between tracer concentrations at particular times for model and field data is often poor, modelpredicted mean $\left(\overline{C_{N}}\right)$ and standard deviation $\left(s_{C_{N}}\right)$ are similar to field measurements when data are compared over the same time intervals. At $2.5 \mathrm{~m} \mathrm{AGL}, \overline{C_{N}}=0.19\left(s_{C_{N}}=0.15\right)$ and $\overline{C_{N}}=0.21$ $\left(s_{C_{N}}=0.17\right)$ for model and observation, respectively. At $85 \mathrm{~m} \mathrm{AGL}$, the match is not quite as good with $\overline{C_{N}}=0.12\left(s_{C_{N}}=0.19\right)$ and $\overline{C_{N}}=0.19\left(s_{C_{N}}=0.20\right)$ for model and observation, respectively. At $2.5 \mathrm{~m}$ AGL field data have sharper gradients than model simulation results, suggesting that mixing because of surface roughness was too large in the model. Field data at $2.5 \mathrm{~m}$ AGL may have been affected by vehicular sources of $\mathrm{C}_{2} \mathrm{H}_{2}$ too, which would have resulted in some of the data spikes. Because the atmospheric dispersion model provided a reasonable match to field wind 
324 measurements and tracer data, the model was subsequently used to estimate the travel time from

325 the landfill and to test three hypotheses about the effect of wind on TDM measurements.

$326 \quad$ Figure 3

$327 \quad$ Figure 4

$328 \quad 3.3$ Travel time

Estimates of travel time are necessary to correlate wind speed at the landfill surface to the corresponding time of TDM-measured $\mathrm{CH}_{4}$ emissions for testing three hypotheses about the influence of wind on $\mathrm{CH}_{4}$ emissions. Travel times from the landfill surface to the downwind measurement location were computed using the methodology described in Supporting Information increments (15 sec, 1, 15 and $30 \mathrm{~min}$ ) to assess the impact of 1-min averaging on travel time calculations. Travel times ranged from approximately 5 to $16 \mathrm{~min}$ at the finest resolutions (15-sec

337 and 1-min averaging increments), with minimal differences between 15-sec and 1-min wind speed 338 averaging (see Figure 5). Thus, in the analyses below 1-min average wind speeds were used to compute travel times for all analyses.

$340 \quad$ Figure 5

$\bar{V}(t)$ were determined for consecutive 1-min time increments at the landfill surface and 342 this information propagated to the downwind measurement location by adding the travel time $T(t)$, 343 thus providing wind speed at the downwind location to correlate with measured $\mathrm{CH}_{4}$ emissions. 344 However, because of variability in travel time this sometimes resulted in multivalued $\bar{V}(t+T(t))$ 345 at the downwind location: more than one wind speed on the landfill surface affected downwind $346 C_{\mathrm{CH}_{4}}$ at such times. At such times downwind concentrations were influenced by emissions from at 
347 least two different 1-min time periods on the landfill surface. These multivalued wind speed and

348 associated 1-min emissions data were excluded from all subsequent analyses.

\subsection{Data filtering and testing hypothesis 1: Homogeneous but transient emissions}

Data filtering techniques were developed for TDM-measured $\mathrm{CH}_{4}$ emissions using the atmospheric dispersion model simulations. In these simulations, $\mathrm{CH}_{4}$ emissions are known and between $\mathrm{CH}_{4}$ emissions and wind speed emissions data were grouped into consecutive 1-min intervals for simulations too, which facilitated comparison between the simulation and field 357 results.

To develop the data filtering methods, data without any filtering were first considered. To

359 illustrate the procedure, consider simulation pair VF2/CF1 where VF2 represents time-varying $360 \mathrm{CH}_{4}$ emissions that are linearly related to wind speed (equation (7)), while CF1 represents a constant tracer emission that is perfectly aligned with $\mathrm{CH}_{4}$ emissions (equation (3)) from Area C

362 at Sandtown Landfill. The purpose of this comparison is to determine the role of wind speed on 363 TDM-measured $\mathrm{CH}_{4}$ emissions, by comparing to a tracer that is perfectly aligned but not wind 364 dependent. The 2 s numerical simulation data showing variable $\mathrm{CH}_{4}$ emissions at the landfill 365 surface and corresponding downwind VF2/CF1 emissions measurement at $2.5 \mathrm{~m}$ are shown in 366 Figure 6. Downwind measurements lag emissions on the landfill surface because of gas plume transit. The $2 \mathrm{~s}$ downwind VF2/CF1 measurements are less variable than actual emissions because 368 of atmospheric mixing, which smooths the peaks and valleys of concentrations at the landfill 369 surface. 
Figure 6

The $2 \mathrm{~s}$ data were grouped into consecutive 1-min time intervals; concentrations below $0.1 \%$ of maximum model concentrations on the landfill surface were associated with numerical error and discarded. The remaining data in each scatter plot of VF2 versus CF1 measurements were linearly regressed and the slope of the best-fit line used to estimate $C_{\mathrm{CH}_{4}} / C_{C_{2} \mathrm{H}_{2}}$ in equation (1) to calculate $\mathrm{CH}_{4}$ emissions during each 1-min interval. An example scatter plot is shown in Figure S3 and further discussed in Supporting Information.

To examine the relationship between $\mathrm{CH}_{4}$ emissions and wind speed on the landfill surface, the average wind speed over the region of $\mathrm{CH}_{4}$ emissions was first determined for each 1-min time interval: $\bar{V}(t)=\int_{t-0.5 \min }^{t+0.5 \mathrm{~min}} V_{m}\left(t^{\prime}\right) d t^{\prime} / 1 \mathrm{~min}$, where $V_{m}$ is the wind speed at the wind monitor location interpolated from the model grid. This wind speed was propagated to the downwind measurement location by adding the travel time $\bar{V}(t+T(t))$. Wind speed data were linearly interpolated to provide the wind speed that corresponded to the midpoint of each 1-min emissions measurement. $\mathrm{CH}_{4}$ emissions were then normalized with the average emission over the 2-h simulation time and plotted in Figure 7 for each 1-min time increment versus wind speed, also normalized with the average wind speed over $2 \mathrm{~h}$. Data at 2.5 and $85 \mathrm{~m}$ AGL were correlated with wind speed $\left(R^{2}=0.39\right.$ and $\left.R^{2}=0.31\right)$, but the correlation was not strong and emissions did not vary with a slope close to 1.0 for $85 \mathrm{~m}$ data, as would be expected from equation (7).

Because the 1:1 relationship between $\mathrm{CH}_{4}$ emissions and wind speed was specified in simulation VF2 (see equation (7)) but was not reproduced with the TDM for data at $85 \mathrm{~m}$, data filtering techniques were explored. Foster-Wittig et al (2015) and Monster et al. (2014) examined data analysis procedures for TDM-measured $\mathrm{CH}_{4}$ emissions. Using downwind transects of landfill gas plumes, Foster-Wittig et al. (2015) developed three method quality indicators to determine if 
393

394

395

396

397

398

399

400

401

402

403

404

405

406

407

408

409

410

411

412

413

414

415

measurements were acceptable: signal to noise ratio $>10, R^{2}>0.80$ for correlation between $C_{C_{4}}$ and $C_{C_{2} H_{2}}$ during the transect, and normalized difference in emissions measurement between regression of scatter plot data versus integration of the gas plumes $<0.20$. While a formal data quality analysis procedure was not developed by Mønster et al. (2014), they recommended the plume integration method over three alternative analysis procedures, with measurement uncertainty determined by replicate sampling of the gas plumes.

\section{Figure 7}

In this work measurements were made at a fixed spatial location, so the data filtering steps developed by Foster-Wittig et al. (2015) are not directly applicable. Nevertheless, the goodness of fit criterion used by Foster-Wittig et al. (2015) was applied: data were only used if $R^{2}>0.80$ for 1-min linear regressions of $C_{C_{4}}$ versus $C_{C_{2} H_{2}}$. During periods of rapid wind speed variation, linearly interpolated wind speed assigned to each 1-min emissions measurement might result in a poor estimate of actual wind speed. Linear interpolation is reasonable only if wind speed varies smoothly with time, which was assessed by examining the second derivative of wind speed with respect to time. Linearly interpolated wind speed data were excluded if $\mid\left(\bar{V}\left(t_{2}\right)-2 \bar{V}\left(t_{1}\right)+\right.$ $\left.\bar{V}\left(t_{0}\right)\right) /(2 \overline{\bar{V}}) \mid>0.175$, where this finite difference expression approximates the second derivative of the wind speed at time $t_{1}$ using data at times $t_{0}, t_{1}$, and $t_{2}$, multiplied by the time increment $(\Delta t)^{2}$, and normalized by the mean wind speed over the 2 -h measurement period. The 0.175 criterion was selected based on a visual assessment of the data; the sensitivity of the results to this criterion and $R^{2}>0.80$ was examined and is discussed in Supporting Information.

Applying these filtering criteria to the simulation pair VF2/CF1 (raw data in Figure 7) resulted in the 1-min emissions versus wind speed data in Figure 8. Filtering had a minor effect on measurements at $2.5 \mathrm{~m} \mathrm{AGL:} R^{2}$ decreased slightly from 0.39 to 0.35 , while there was a small 
416 change in slope from $0.89 \pm 0.28$ to $0.85 \pm 0.38$. Filtering improved the results at $85 \mathrm{~m}$ AGL:

$417 R^{2}$ increased from 0.31 to 0.56 and the slope increased from $0.43 \pm 0.20$ to $0.67 \pm 0.24$. Filtering

418 criteria had a more noticeable effect on airborne than ground data because gas concentrations were

419 smaller at $85 \mathrm{~m}$, and smaller gas concentrations rendered emissions estimation more susceptible

420 to error. While the TDM measurements at both heights do not reproduce the 1:1 relationship

421 between emissions and wind speed that was specified in the model, $\mathrm{CH}_{4}$ emissions clearly increase

422 with wind speed. Thus, hypothesis \#1 cannot be disproved: if local $\mathrm{CH}_{4}$ emissions vary with wind

423 speed causing wind-induced variations of whole landfill emissions, TDM emissions measurements

424 may also be correlated with wind speed.

$425 \quad$ Figure 8

426

The failure to reproduce the 1:1 relationship between emissions and wind speed is

427 associated, we believe, with mixing of high and low emissions plumes between successive

428 sampling times. This effect is illustrated with the $2 \mathrm{~s}$ data in Figure 6: high actual emissions are

429 slightly underpredicted with VF2/CF1 downwind measurements, while low actual emissions are

430 overpredicted. This effect can be described mathematically

$$
C_{C H_{4}}^{\text {low }}<C_{C H_{4}}^{\text {downwind }}=\frac{C_{C H_{4}}^{\text {high }} \times P^{\text {high }}+C_{C H_{4}}^{\text {low }} \times P^{\text {low }}}{P^{\text {high }}+P^{\text {low }}}<C_{\mathrm{CH}_{4}}^{\text {high }}
$$

432 where $C_{\mathrm{CH}_{4}}^{\text {high }}$ and $C_{\mathrm{CH}_{4}}^{\text {low }}$ are mean $\mathrm{CH}_{4}$ concentrations in downwind plumes during high and low 433 emissions, respectively, and $P^{\text {high }}$ and $P^{\text {low }}$ are plume volumes correspond to $C_{C H_{4}}^{\text {high }}$ and $C_{C H_{4}}^{\text {low }}$

434 emissions periods. Gas plumes from the landfill move at different speeds because of wind speed 435 variations. If portions of these plumes mix by the time they reach the downwind measurement 436 location, observed $C_{C H_{4}}^{\text {downwind }}$ will be a weighted average concentration of the two plumes and fall 437 between $C_{\mathrm{CH}_{4}}^{\text {high }}$ and $\mathrm{C}_{\mathrm{CH}_{4}}^{\text {low }}$. Thus, high $\mathrm{CH}_{4}$ emissions will be slightly underestimated and low $\mathrm{CH}_{4}$ 

442 AGL.

emissions slightly overestimated because of plume mixing, and the observed sensitivity of emissions with wind speed using downwind data will be less than at the landfill surface. This is the reason that the 1:1 relationship between emissions and wind speed imposed in the VF2/CF1 simulation may be less than 1:1 (slope less than 1) for downwind measurements at 2.5 and $85 \mathrm{~m}$

\subsection{Testing hypothesis 2: Heterogeneous but steady emissions}

It is possible that TDM-measured $\mathrm{CH}_{4}$ emissions might exhibit a correlation with wind speed on the landfill surface if local $\mathrm{CH}_{4}$ emissions vary with wind speed even if whole landfill emissions are constant. The simulation pair VF1/CF1 was used to test this hypothesis, where VF1 represents spatially-varying $\mathrm{CH}_{4}$ emissions due to local variations in wind speed (equation (6)) and $\mathrm{CF} 1$ represents a constant tracer emission perfectly aligned with $\mathrm{CH}_{4}$ emission (equation (3)). Data from the VF1/CF1 simulation pair were filtered as described above and results are plotted in Figure 9. For measurements at 2.5 and $85 \mathrm{~m} \mathrm{AGL}$, emissions are not correlated with wind speed: $R^{2}=0.02$ and 0.011 for 2.5 and $85 \mathrm{~m}$ AGL, respectively. These results are relatively insensitive to filtering, with $R^{2} \leq 0.14$ for all conditions examined (see Table 1 and Table S3 in Supporting Information). Thus, hypothesis \#2 is disproved: if local $\mathrm{CH}_{4}$ emissions vary with wind speed but whole landfill emissions are constant, TDM emissions measurements will not be correlated with wind speed.

\section{Figure 9}

\subsection{Testing hypothesis 3: Steady emissions and misalignment of tracer}

For steady $\mathrm{CH}_{4}$ emissions, misalignment of tracer and $\mathrm{CH}_{4}$ emissions locations may cause TDM-measured emissions to exhibit a correlation with wind speed. The simulation pairs CF1/3Pts and $\mathrm{CF} 2 / 3$ Pts were used to test this hypothesis, where for these simulation pairs alone $\mathrm{CF} 1$ and 
$461 \mathrm{CF} 2$ represented spatially uniform and temporally constant $\mathrm{CH}_{4}$ emissions (equations (3) and (4)),

462 and 3Pts represented constant tracer emissions from three locations corresponding to field tracer

463 release points (equation (2)). Misalignment of CF1 and 3Pts was primarily parallel to the mean

464 wind direction, while $\mathrm{CF} 2$ and 3Pts were misaligned perpendicular to the mean wind direction (see

465 Figure 1). The centers of CF1 and 3Pts, or CF2 and 3Pts emission sources were $250 \mathrm{~m}$ or $175 \mathrm{~m}$

466 apart, respectively.

467 Data from the CF1/3Pts simulation pair were filtered following the procedures described

468 above and results are shown in Figure 10. For measurements at 2.5 and $85 \mathrm{~m}$ AGL, emissions are

469 not correlated with wind speed: $R^{2}=0.001$ and 0.05 for 2.5 and $85 \mathrm{~m}$ AGL, respectively. These

470 results are insensitive to filtering, with $R^{2} \leq 0.06$ for all conditions examined (see Table 1 and

471 Table S3 in Supporting Information). Similar results were found for CF2/3Pts and are shown in

472 Figure S4, with the effects of data filtering presented in Table 1 and Table S3. Tracer misalignment

473 parallel (CF1/3Pts) or perpendicular (CF2/3Pts) to the mean wind direction did not result in a

474 statistical meaningful relationship between wind speed and $\mathrm{CH}_{4}$ emissions. Thus, hypothesis \#3 is

475 disproved: if local $\mathrm{CH}_{4}$ emissions are constant but significantly misaligned with tracer emission

476 locations, TDM emissions measurements will not be correlated with wind speed.

$477 \quad \underline{\text { Figure } 10}$

$478 \quad 3.7$ Field emissions correlation with wind

479 Atmospheric dispersion model simulations indicate that for the conditions at Sandtown

480 Landfill on March 6, 2010, if $\mathrm{CH}_{4}$ emissions vary with wind speed at the landfill surface a 481 correlation between emissions and wind speed might be detected with TDM. TDM data from the

482 field test at Sandtown Landfill were analyzed to assess if $\mathrm{CH}_{4}$ emissions were correlated with wind 483 speed. Here, the same data filtering techniques developed for the model simulations were applied. 
484 A sensitivity analysis of the results to the filtering criteria is discussed in Supporting Information.

485 The travel times from landfill surface to measurement location were determined using simulation

4863 Pts, since tracer emissions were not dependent on wind speed and located in close proximity to

487 actual field tracer release points, therefore accurately tracking the wind path. $\bar{V}(t)$ at the landfill

488 surface was taken from wind monitor data.

489 The results from this analysis are shown in Figure 11. As with the simulations, data are 490 normalized with mean $\mathrm{CH}_{4}$ emissions (emissions data) or mean wind speed (wind data) to facilitate 491 comparison with simulation results. There are fewer data points from the field compared to 492 simulations for two reasons. First, field data were only collected for 18 and 31 1-min measurement 493 windows at 2.5 and $85 \mathrm{~m}$ AGL, respectively, while simulation data were available for 120 1-min 494 measurement windows at both heights. Second, there was more scatter in gas concentrations in the 495 field data than in the simulations, likely because of greater small-scale mixing in the field that was 496 not captured with the model. This resulted in visible error bars for field data in Figure 11 and more 497 data that violated the $R^{2}>0.80$ criterion. An example field data scatter plot is shown in Figure 498 S5.

At 2.5 and $85 \mathrm{~m}$ AGL field data were positively correlated with wind speed: $R^{2}=0.51$ and $500 R^{2}=0.55$, respectively. However, the data are sparse at $2.5 \mathrm{~m}$ and it is difficult to draw conclusions 501 about the wind dependency of emissions at this height. While linear regressions were used to 502 evaluate the relationship between wind speed and emissions, the actual relationship may be 503 nonlinear. The variations of emissions with wind speed can be compared with previous 504 measurements over a portion of a landfill (McBain et al., 2005). McBain et al. (2005), found 505 emissions linearly correlated with wind speed between $\approx 1.3$ to $5.8 \mathrm{~m} / \mathrm{sec}\left(R^{2}=0.48\right)$ with the 506 slope of normalized mission versus normalized wind speed approximately 0.67 . The correlation 
507 with wind speed in this field study was similar to that of (McBain et al., 2005), although the 508 sensitivity of emissions to wind speed was greater here with the slope of the regressed line $2.00 \pm$ 5095.94 and $2.20 \pm 1.63$ at 2.5 and $85 \mathrm{~m}$ AGL, respectively.

$510 \quad$ Figure 11

The greater sensitivity of $\mathrm{CH}_{4}$ emissions to wind speed at Sandtown Landfill versus that

512 determined by McBain et al. (2005) may have been due to wet landfill conditions at Sandtown.

513 Although the landfill cover soil moisture was not quantified during the Sandtown Landfill field

514 test, the landfill and landfill cover were wet with some near-surface gas collection wells clogged

515 with leachate (Munyan, 2010). Conversely, McBain et al. (2005) reported that their landfill cover

516 soil was dry. Gas pressure fluctuations at the landfill surface caused by wind turbulence and their

517 impact on landfill gas emissions were simulated by Poulsen and Moldrup (2006). In a sensitivity

518 analysis, Poulsen and Moldrup (2006) showed that wind-induced landfill gas fluxes were more

519 significant for wet conditions when air-filled porosities were small. Although total gas fluxes are

520 likely smaller in wet landfill covers because of the reduction in gas permeability and gas diffusion

521 through the soil, Poulsen and Moldrup (2006) found that the relative importance of wind on

522 emissions is more significant for such conditions. Thus, the greater sensitivity of TDM-measured

523 emissions to wind speed in this study than that found by McBain et al. (2005) for eddy covariance

524 measurements may have been due to a wetter cover soil at Sandtown Landfill.

525

Because McBain et al. (2005) showed wind-induced landfill gas emissions could be

526 important for wind speeds greater than or equal to $1.3 \mathrm{~m} / \mathrm{sec}$ and since the tracer dilution method

527 typically requires wind speeds greater than $1 \mathrm{~m} / \mathrm{sec}$ (Jakober et al., 2015), landfill emissions

528 measured using TDM may be affected by wind. Therefore, TDM emissions measurements may be 
systematically higher than $\mathrm{CH}_{4}$ emissions averaged over periods of high and low wind speed conditions at some landfills.

\section{Summary and conclusions}

The objectives of this work were to determine if short-term variations in whole-landfill $\mathrm{CH}_{4}$ emissions measured with TDM might be due to variation of wind speed, and to evaluate the utility of atmospheric dispersion modeling for understanding the influence of atmospheric conditions on emissions measurements. A field experiment was conducted at the Sandtown Landfill, Delaware, and an atmospheric model developed for the site that described atmospheric conditions and gas plume transport. This is the first application of an atmospheric dispersion model to a landfill for understanding gas transport patterns that we are aware of. The atmospheric model provided a reasonable match to measured wind speed and direction on the landfill surface and downwind tracer concentration at the measurement location.

The atmospheric model was then used to generate synthetic data and examine the correlation between TDM-measured $\mathrm{CH}_{4}$ emissions and wind speed on the landfill surface at Sandtown Landfill. Three hypotheses were tested: TDM emissions measurements will be correlated with wind speed if (1) local $\mathrm{CH}_{4}$ emissions vary with wind speed causing wind-induced variations of whole landfill emissions, (2) if the spatial distribution of $\mathrm{CH}_{4}$ emissions varies with wind speed but whole landfill emissions are constant, and (3) if local $\mathrm{CH}_{4}$ emissions are constant but significantly misaligned with tracer emissions locations. Using computer simulations the only hypothesis not disproved at Sandtown Landfill was hypothesis (1), indicating that wind-induced variations of whole landfill emissions could result in similar variations in TDM emissions measurements. Using the travel times between the landfill and the downwind measurement 
552 location from the atmospheric dispersion model, field data were analyzed and showed a correlation

553 between emissions and wind speed on the landfill surface, with emissions increasing by a factor 554 of 2 as wind speed increased by approximately 30\% (85 m AGL data). Higher gas concentrations 555 and a larger signal to noise ratio were observed for data collected at $85 \mathrm{~m}$ than $2.5 \mathrm{~m}$ AGL. Thus, 556 for some landfills and atmospheric conditions, measurements significantly above ground level may 557 result in more accurate emissions estimates.

This study examined $\mathrm{CH}_{4}$ emissions for a 2-h measurement period from a single landfill.

559 While the results indicate that short-term variations in emissions determined from TDM were 560 likely due to wind speed variations on the landfill surface, the significance of this effect for whole561 landfill emissions at other landfills is unknown. Future study at other landfills is needed before 562 generalizing this result. Based on the work of Poulsen and Moldrup (2006), wind-induced 563 emissions will be more important for wet landfill covers with small air-filled porosity and for high 564 wind speeds, where wind-induced turbulence is greater.

565 If indeed $\mathrm{CH}_{4}$ emissions from landfills are wind dependent for some landfill cover 566 conditions, landfill gas management might be altered to improve gas collection under such 567 conditions. For example, under windy conditions for a wet landfill cover when emissions are 568 expected to be more sensitive to wind speed, landfill gas extraction might be increased to decrease $569 \mathrm{CH}_{4}$ concentrations in cover soils that would result in a reduction in emissions. This might be 570 feasible without causing undesired air ingress into the landfill, since soil gas permeability 571 decreases significantly as cover soils become wet (Poulsen and Moldrup, 2006). In addition, if $572 \mathrm{CH}_{4}$ emissions from landfills are wind dependent, care should be exercised in extrapolating whole573 landfill emission measurements made under particular wind conditions to emissions under 574 different atmospheric conditions. 
576

577 Acknowledgements

578 The authors gratefully acknowledge the assistance of Erfan Mostafid, Vince Scicchitano, and

579 Michael Davidson from the University of Delaware. Dan Fluman from the Delaware Solid Waste 580 Authority collected the wind data from the Sandtown Landfill. Roger Green from Waste 581 Management, Inc. supplied equipment for the tracer gas release and guidance for field 582 experimentation. Support from this research was provided by the University of Delaware Research 583 Foundation through a Strategic Initiatives Grant and from the US Department of Energy under 584 Cooperative Agreement DE-FC26-05NT42432. Authors BZ and FKC are grateful for support 585 from National Science Foundation Grant ATM- 0645784 (Physical and Dynamic Meteorology 586 Program).

587 


\section{References}

589 Allen, M.R., Braithwaite, A., Hills, C.C., 1997. Trace organic compounds in landfill gas at seven 590 UK waste disposal sites. Environmental science \& technology 31, 1054-1061.

591 Börjesson, G., Samuelsson, J., Chanton, J., Adolfsson, R., Galle, B., Svensson, B.H., 2009. A

592 national landfill methane budget for sweden based on field measurements, and an evaluation of 593 IPCC models. Tellus B 61, 424-435.

594 Chanton, J. and Liptay, K., 2000. Seasonal variation in methane oxidation in a landfill cover soil 595 as determined by an in situ stable isotope technique. Global Biogeochemical Cycles 14, 51-60.

596 Crosson, E., 2008. A cavity ring-down analyzer for measuring atmospheric levels of methane, 597 carbon dioxide, and water vapor. Applied Physics B 92, 403-408.

598 Czepiel, P., Shorter, J., Mosher, B., Allwine, E., McManus, J., Harriss, R., Kolb, C., Lamb, B., 599 2003. The influence of atmospheric pressure on landfill methane emissions. Waste Management $600 \quad 23,593-598$.

601 Deleersnijder, E., Campin, J., Delhez, E.J., 2001. The concept of age in marine modelling: I. 602 theory and preliminary model results. Journal of Marine Systems 28, 229-267.

603 Foster-Wittig, T.A., Thoma, E.D., Green, R.B., Hater, G.R., Swan, N.D., Chanton, J.P., 2015. 604 Development of a mobile tracer correlation method for assessment of air emissions from landfills 605 and other area sources. Atmospheric Environment 102, 323-330. 
606 Galle, B., Samuelsson, J., Svensson, B.H., Börjesson, G., 2001. Measurements of methane

607 emissions from landfills using a time correlation tracer method based on FTIR absorption

608 spectroscopy. Environmental science \& technology 35, 21-25.

609 Green, R.B., Hater, G.R., Thoma, E.D., DeWees, J., Rella, C.W., Crosson, E.R., Goldsmith,

610 C.D., Swan, N., 2010. Methane emissions measured at two California landfills by OTM-10 and

611 an acetylene tracer method. In: Proceedings of the Global Waste Management Symposium, 3-6.

612 Jakober, C.A., Mara, S.L., Hsu, Y., Herner, J.D., 2015. Mobile measurements of climate forcing

613 agents: Application to methane emissions from landfill and natural gas compression. Journal of

614 the Air \& Waste Management Association 65, 404-412.

615 McBain, M.C., Warland, J.S., McBride, R.A., Wagner-Riddle, C., 2005. Micrometeorological

616 measurements of $\mathrm{N} 2 \mathrm{O}$ and $\mathrm{CH} 4$ emissions from a municipal solid waste landfill. Waste

617 management \& research : the journal of the International Solid Wastes and Public Cleansing

618 Association, ISWA 23, 409-419.

619 Mønster, J., Samuelsson, J., Kjeldsen, P., Scheutz, C., 2015. Quantification of methane

620 emissions from 15 danish landfills using the mobile tracer dispersion method. Waste

621 Management 35, 177-186.

622 Mønster, J.G., Samuelsson, J., Kjeldsen, P., Rella, C.W., Scheutz, C., 2014. Quantifying methane

623 emission from fugitive sources by combining tracer release and downwind measurements-a

624 sensitivity analysis based on multiple field surveys. Waste Management 34, 1416-1428. 
625 626

627 628 629 630

$637 \quad 1009-1017$.

638 639 oxidation. Waste Management 27, 1248-1258.

643 Wang, J., Xia, F., Bai, Y., Fang, C., Shen, D., He, R., 2011. Methane oxidation in landfill waste 644 biocover soil: Kinetics and sensitivity to ambient conditions. Waste Management 31, 864-870.

Munyan, J., 2010. Delaware Solid Waste Authority, 1128 South Bradford Street, Dover, DE.

Poulsen, T.G. and Moldrup, P., 2006. Evaluating effects of wind-induced pressure fluctuations on soil-atmosphere gas exchange at a landfill using stochastic modelling. Waste management \& research : the journal of the International Solid Wastes and Public Cleansing Association, ISWA $24,473-481$.

Rachor, I., Gebert, J., Gröngröft, A., Pfeiffer, E., 2013. Variability of methane emissions from an old landfill over different time-scales. European Journal of Soil Science 64, 16-26.

Scheehle, E., Godwin, D., Ottinger, D., DeAngelo, B., 2006. Global anthropogenic non-CO2 greenhouse gas emissions: 1990-2020. Version: revised June

Scheutz, C., Samuelsson, J., Fredenslund, A.M., Kjeldsen, P., 2011. Quantification of multiple methane emission sources at landfills using a double tracer technique. Waste Management 31, Shaw, R.H. and Schumann, U., 1992. Large-eddy simulation of turbulent flow above and within a forest. Boundary-Layer Meteorology 61, 47-64.

Stern, J.C., Chanton, J., Abichou, T., Powelson, D., Yuan, L., Escoriza, S., Bogner, J., 2007. Use of a biologically active cover to reduce landfill methane emissions and enhance methane 
645 Weitz, K.A., Thorneloe, S.A., Nishtala, S.R., Yarkosky, S., Zannes, M., 2002. The impact of 646 municipal solid waste management on greenhouse gas emissions in the united states. Journal of 647 the Air \& Waste Management Association 52, 1000-1011.

648 Xu, L., Lin, X., Amen, J., Welding, K., McDermitt, D., 2014. Impact of changes in barometric 649 pressure on landfill methane emission. Global Biogeochemical Cycles 28, 679-695.

650 Xue, M., Droegemeier, K.K., Wong, V., Shapiro, A., Brewster, K., Carr, F., Weber, D., Liu, Y., 651 Wang, D., 2001. The advanced regional prediction system (ARPS)-A multi-scale nonhydrostatic 652 atmospheric simulation and prediction tool. part II: Model physics and applications. Meteorology 653 and atmospheric physics 76, 143-165.

654 Xue, M., Droegemeier, K.K., Wong, V., 2000. The advanced regional prediction system 655 (ARPS)-A multi-scale nonhydrostatic atmospheric simulation and prediction model. part I:

656 Model dynamics and verification. Meteorology and atmospheric physics 75, 161-193.

657

658

659

660

661

662

663

664

665

666

667 
668 Table 1. Linear regression of normalized methane emission versus normalized wind speed for three 669 simulation pairs with and without data filtering.

\begin{tabular}{|c|c|c|c|c|c|c|c|c|}
\hline \multirow{4}{*}{ Simulations } & \multicolumn{8}{|c|}{ Data type } \\
\hline & \multicolumn{4}{|c|}{ Unfiltered } & \multicolumn{4}{|c|}{ Filtered } \\
\hline & \multicolumn{2}{|c|}{ Ground height $(2.5 \mathrm{~m})$} & \multicolumn{2}{|c|}{ Airborne height $(85 \mathrm{~m})$} & \multicolumn{2}{|c|}{ Ground height $(2.5 \mathrm{~m})$} & \multicolumn{2}{|c|}{ Airborne height $(85 \mathrm{~m})$} \\
\hline & Slope $\pm 95 \% C I$ & $R^{2}$ & Slope $\pm 95 \% C I$ & $R^{2}$ & Slope $\pm 95 \% C I$ & $R^{2}$ & Slope $\pm 95 \% C I$ & $R^{2}$ \\
\hline VF1/CF1 & $-0.05 \pm 0.13$ & 0.01 & $0.14 \pm 0.15$ & 0.06 & $-0.08 \pm 0.18$ & 0.02 & $0.19 \pm 0.22$ & 0.11 \\
\hline CF1/3Pts & $-0.20 \pm 0.56$ & 0.008 & $-0.36 \pm 0.47$ & 0.03 & $-0.14 \pm 1.32$ & 0.001 & $-0.58 \pm 0.83$ & 0.05 \\
\hline CF2/3Pts & $-0.81 \pm 2.22$ & 0.006 & $1.51 \pm 6.85$ & 0.003 & $-0.96 \pm 3.78$ & 0.01 & $-2.00 \pm 4.34$ & 0.11 \\
\hline VF2/CF1 & $0.89 \pm 0.28$ & 0.39 & $0.43 \pm .20$ & 0.31 & $0.85 \pm 0.38$ & 0.35 & $0.67 \pm 0.24$ & 0.56 \\
\hline
\end{tabular}

670

671

672

673

674

675

676 


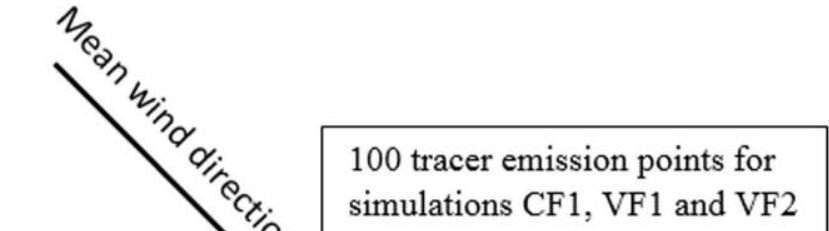

89 tracer emission points for simulation CF2

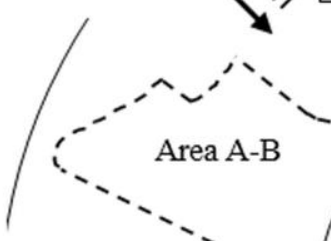
simulations CF1, VF1 and VF2

Figure 1. Aerial view of Sandtown Landfill (Sandtown, DE) illustrating emissions locations for simulations (CF1, CF2, VF1, VF2 and 3Pts) and tracers in field test. The downwind gas sampling location is also shown where measurements were taken at 2.5 and $85 \mathrm{~m}$ AGL. 


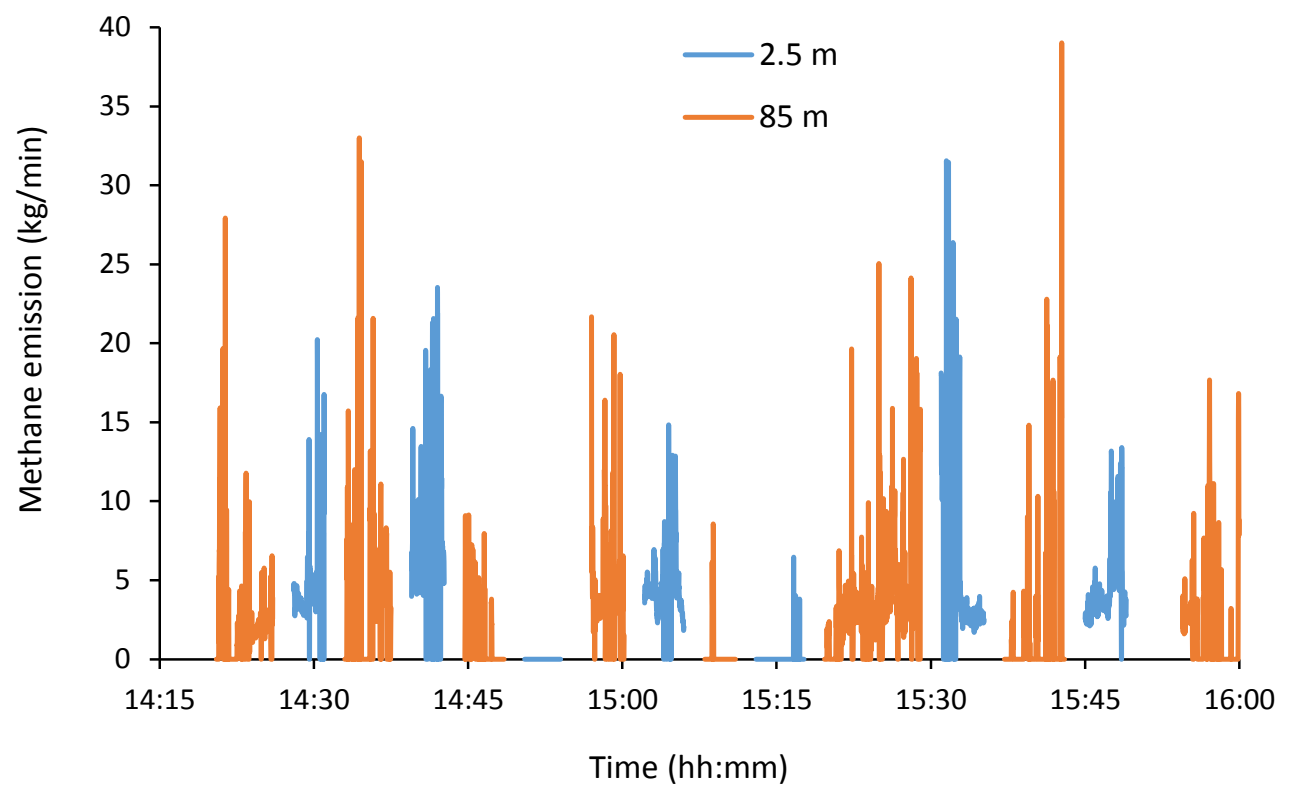

691 Figure 2. Field methane emissions (equation (1)) from individual concentrations at 2.5 (orange) 692 and $85 \mathrm{~m}$ AGL (blue) at downwind measurement location (Figure 1). Each elevation had seven 693 measurement periods. Measured methane emissions were zero when gas concentrations were 694 below background; gaps between measurements correspond to switching sampling tubing between $695 \quad 2.5$ and $85 \mathrm{~m}$ heights.

696

697

698

699

700

701

702 


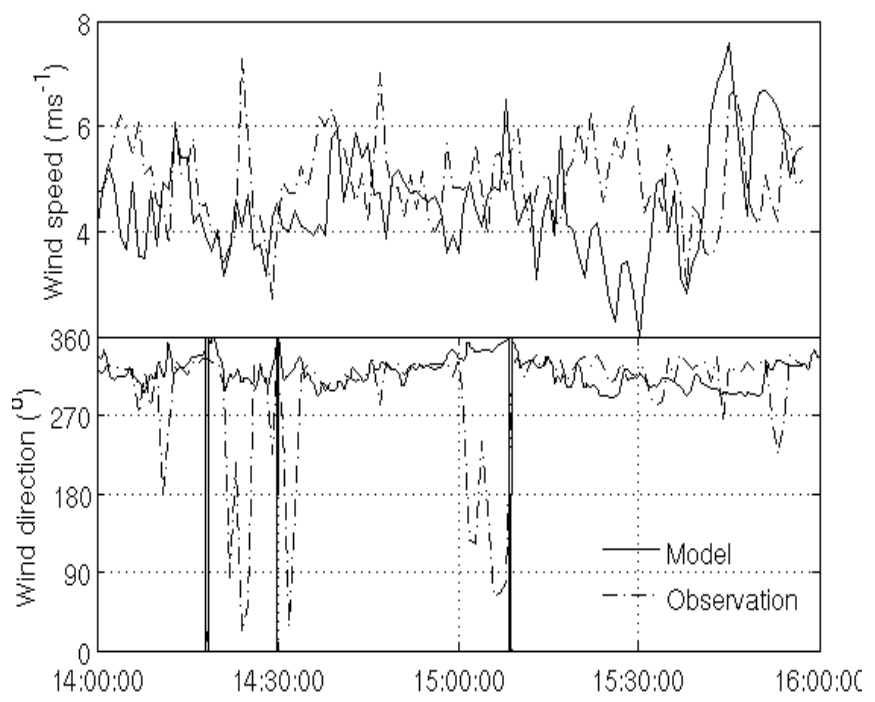

706

707 Figure 3. Times-series of observed and modeled surface wind speed (top) and direction (bottom).

708 Solid lines are model results from the $25 \mathrm{~m}$ grid; dash-dotted lines are observations from surface

709 station

710

711

712

713

714

715

716

717

718

719 


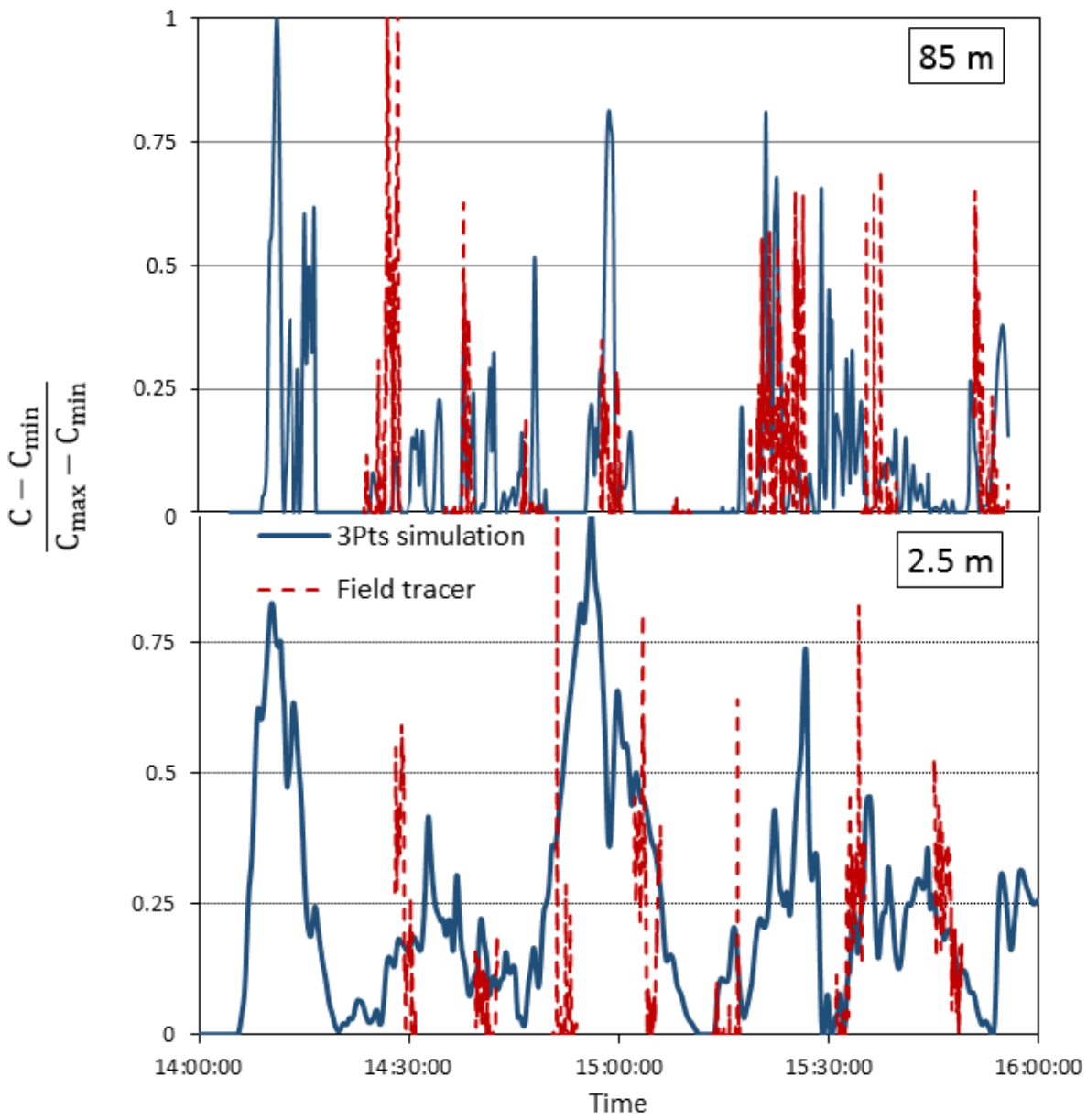

Figure 4. Normalized tracer concentration at downwind measurement location (see Figure 1). Blue solid and red dashed lines are for model (3Pts) and field data, respectively, at 2.5 and 85 m AGL.

726 Gaps between field data correspond to switching sample tubing between 2.5 and $85 \mathrm{~m}$ heights. 


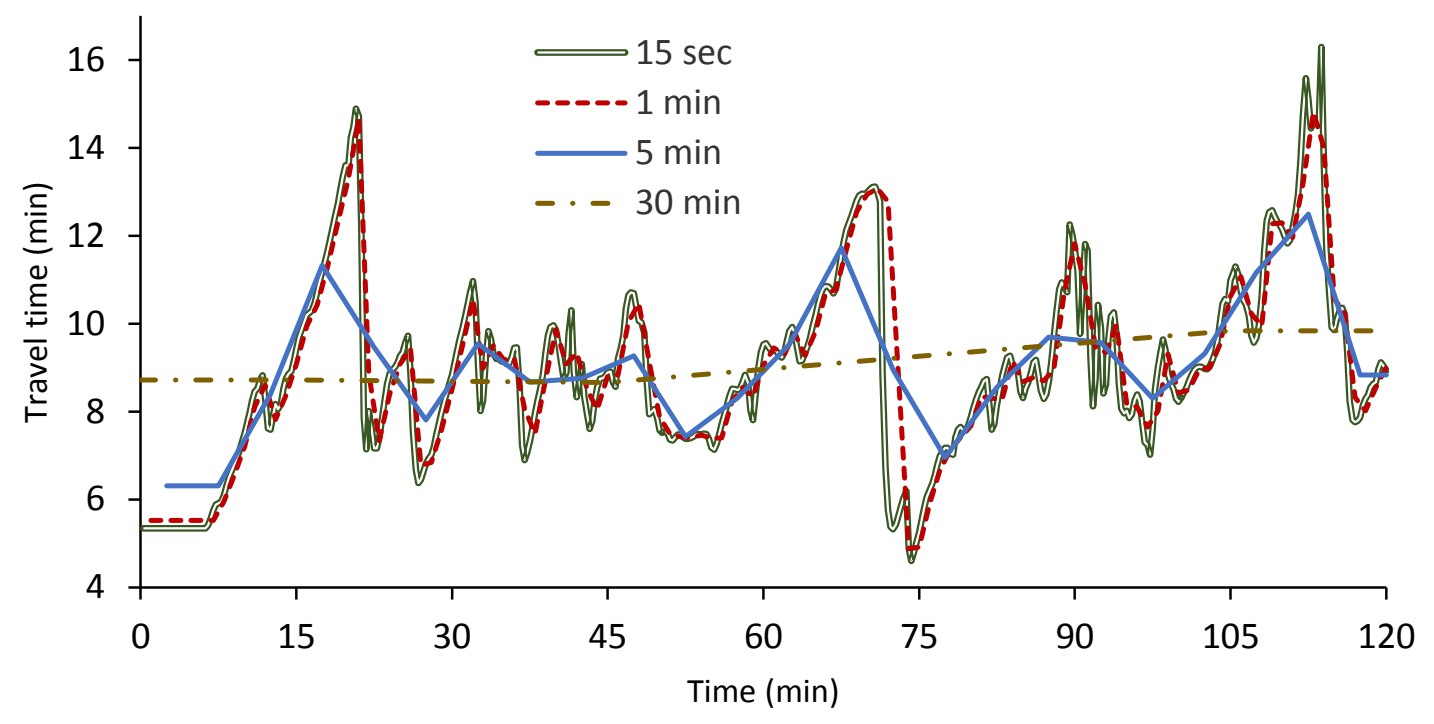

Figure 5. Travel time from landfill to downwind measurement location at $2.5 \mathrm{~m}$ AGL during the resolutions using CF1 simulation.

741

742

743

744

745

746

747

748 


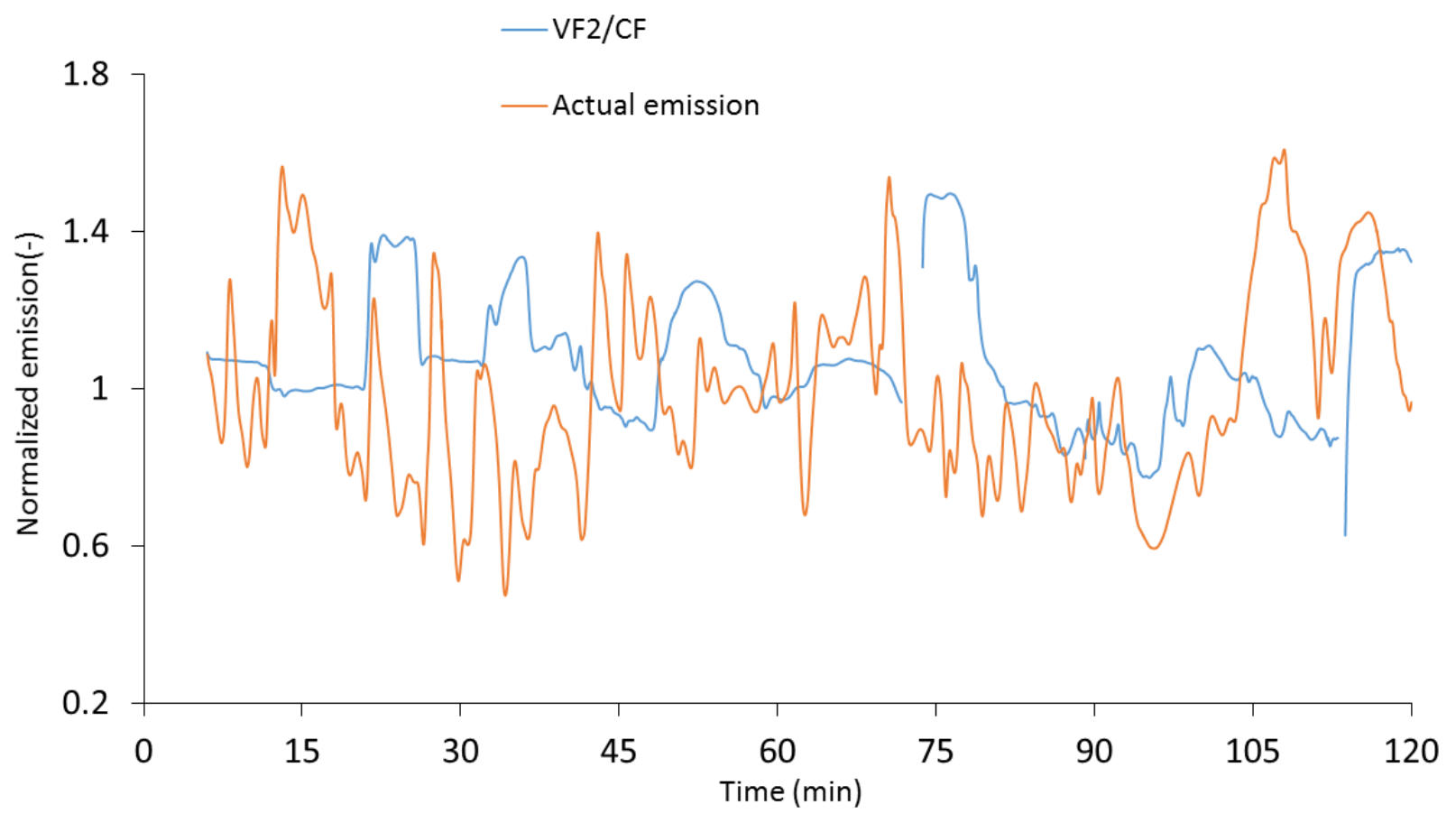

751

752

753

Figure 6. Numerical simulation output. Normalized actual emissions (VF2) and 2 s downwind

754 emissions measurements (VF2/CF1) versus time at 2.5 m AGL with no travel time correction.

755

756

757

758

759

760

761

762

763 

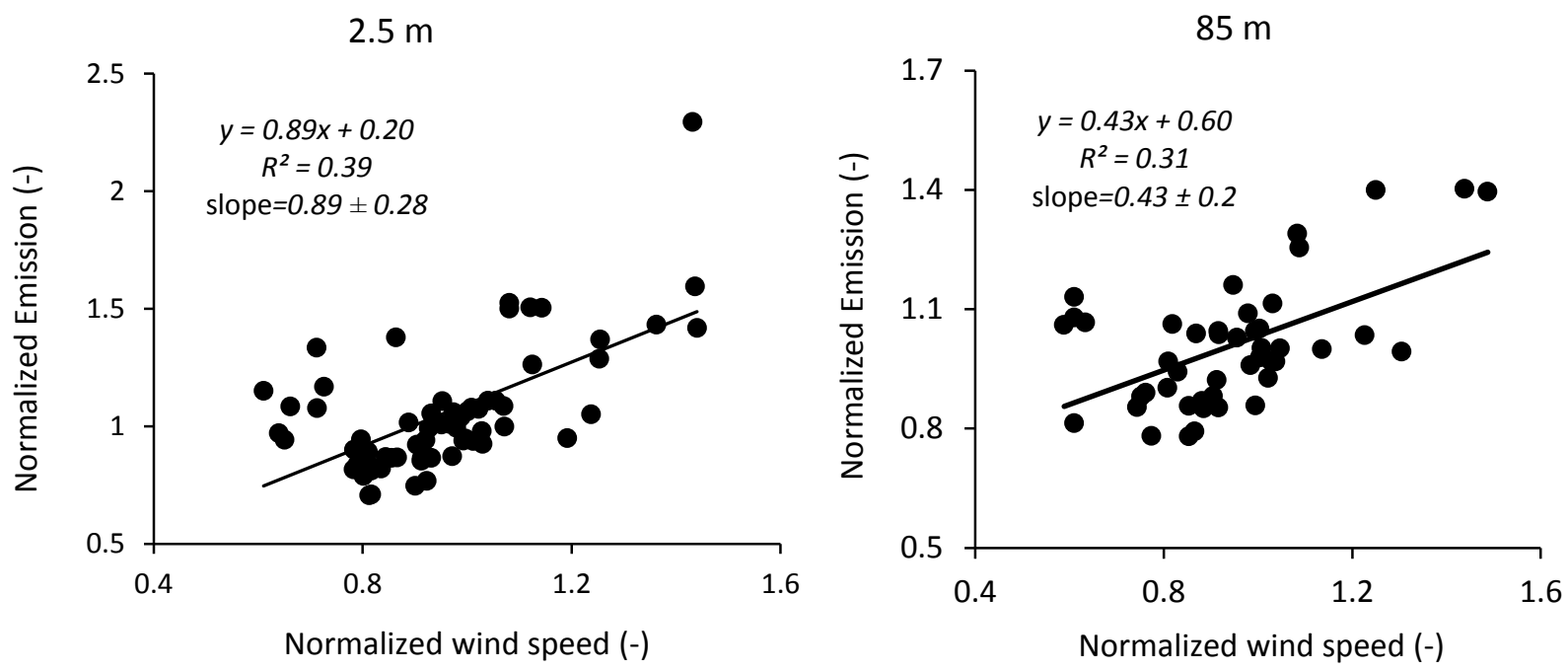

Figure 7. Normalized emissions calculated with TDM using 1-min data from simulation pair VF2/CF1 at 2.5 and $85 \mathrm{~m} \mathrm{AGL}$ at measurement location in Figure 1. Emissions plotted versus normalized wind speed on landfill surface with no data filtering. 95\% confidence intervals on 771 individual data points are so small as not to be visible.

772

773

774

775

776

777

778

779 

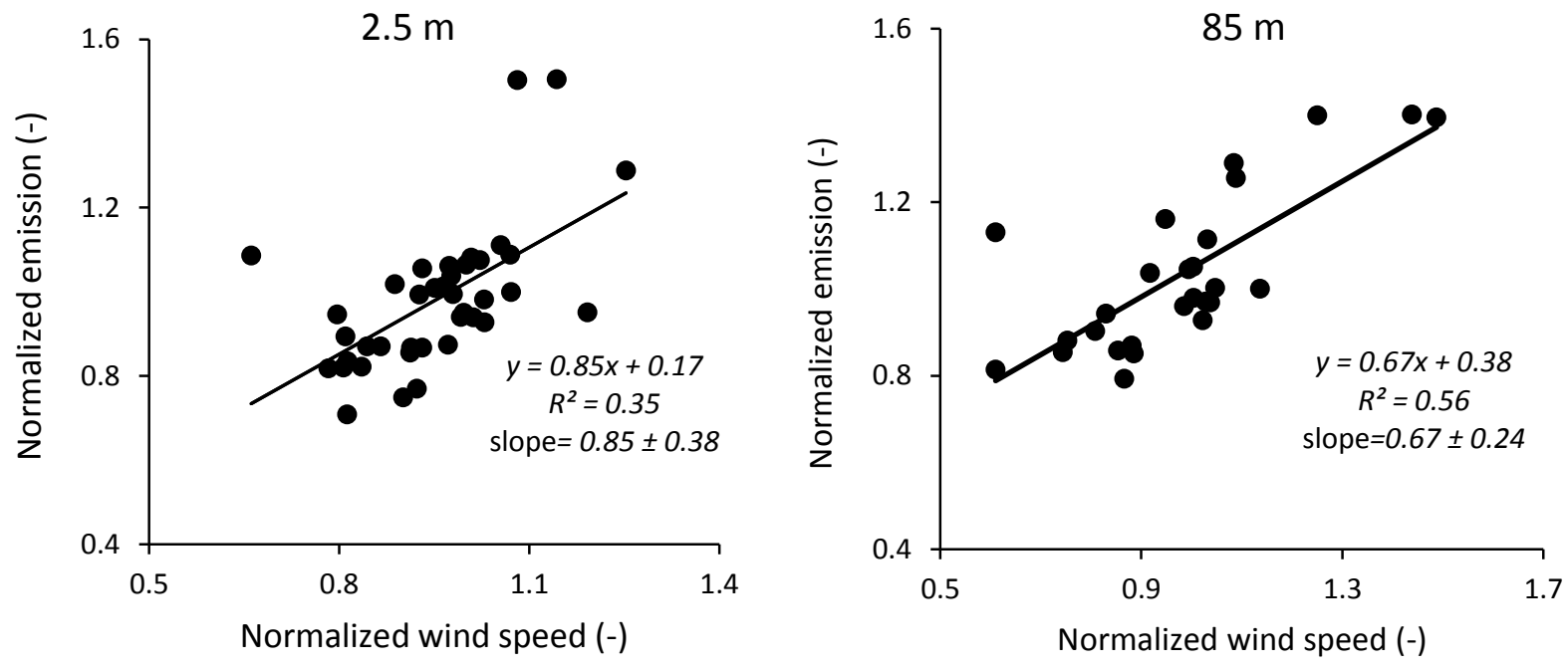

Figure 8. Same as Figure 7 except using data filtering: $R^{2}$ and second derivative of wind velocity criteria. 
800

801
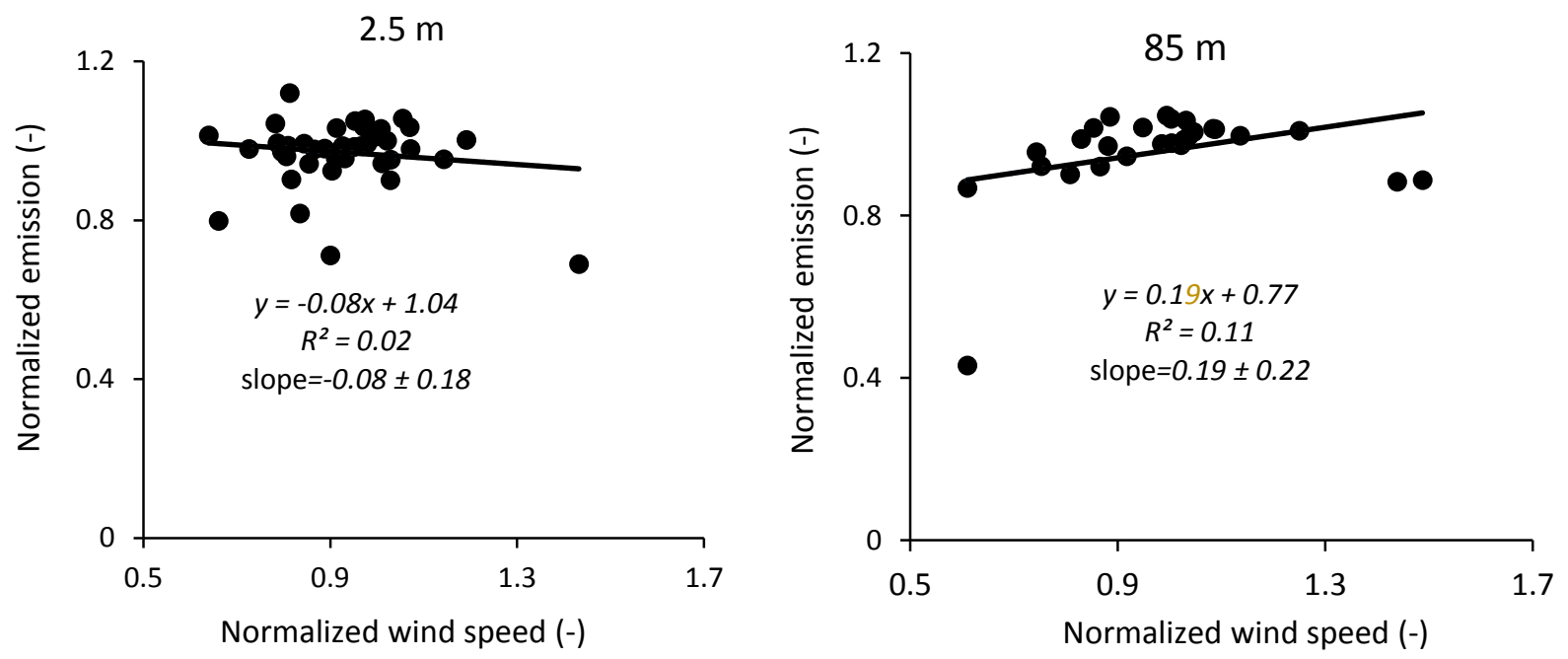

803

804

Figure 9. Normalized emissions calculated with TDM using 1-min data from simulation pair

805 VF1/CF1 at 2.5 and $85 \mathrm{~m}$ AGL at measurement location in Figure 1. Emissions plotted versus normalized wind speed on landfill surface with data filtering: $R^{2}$ and second derivative of wind

807 velocity criteria. 95\% confidence intervals on individual data points are so small as not to be 808 visible.

809

810

811

812

813 

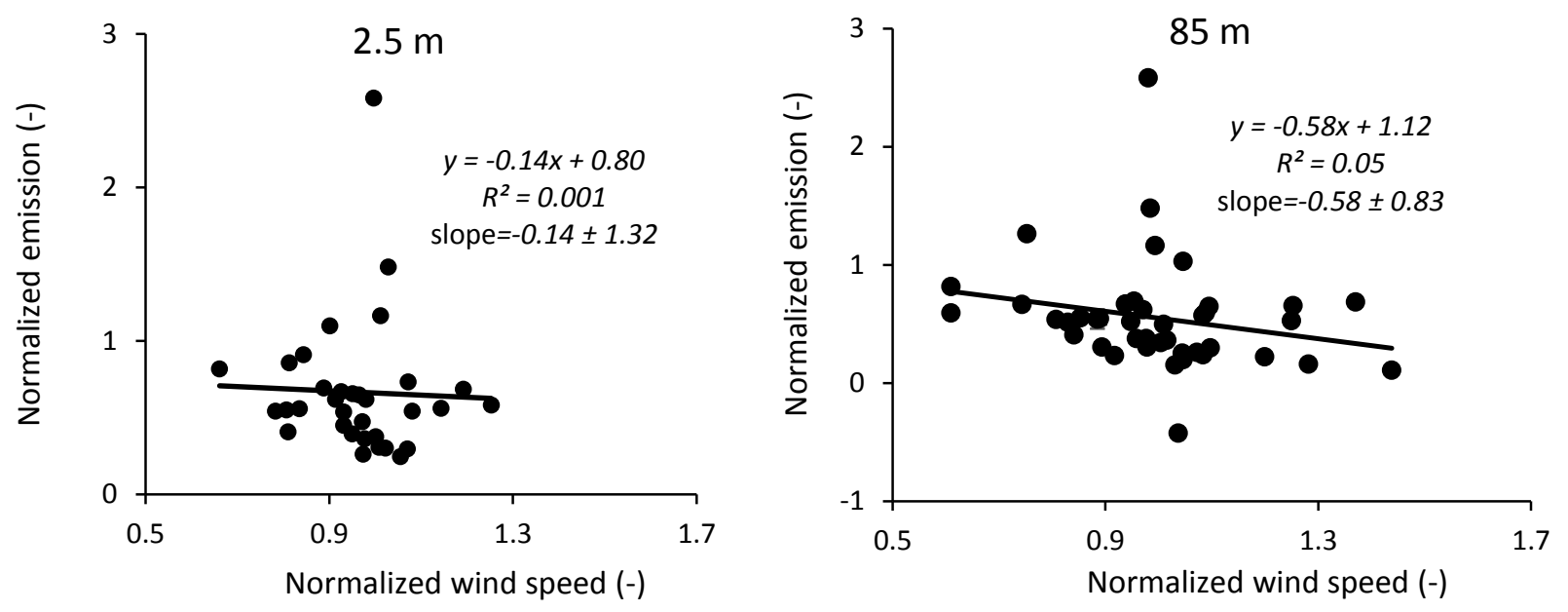

817

818 Figure 10. Normalized emissions calculated with TDM using 1-min data from simulation pair

$819 \mathrm{CF} 1 / 3$ Pts at 2.5 and $85 \mathrm{~m} \mathrm{AGL}$ at measurement location in Figure 1. Emissions plotted versus 820 normalized wind speed on landfill surface with data filtering: $R^{2}$ and second derivative of wind

821 velocity criteria. 95\% confidence intervals on individual data points are so small as not to be 822 visible.

823

824

825

826

827

828

829

830

831 

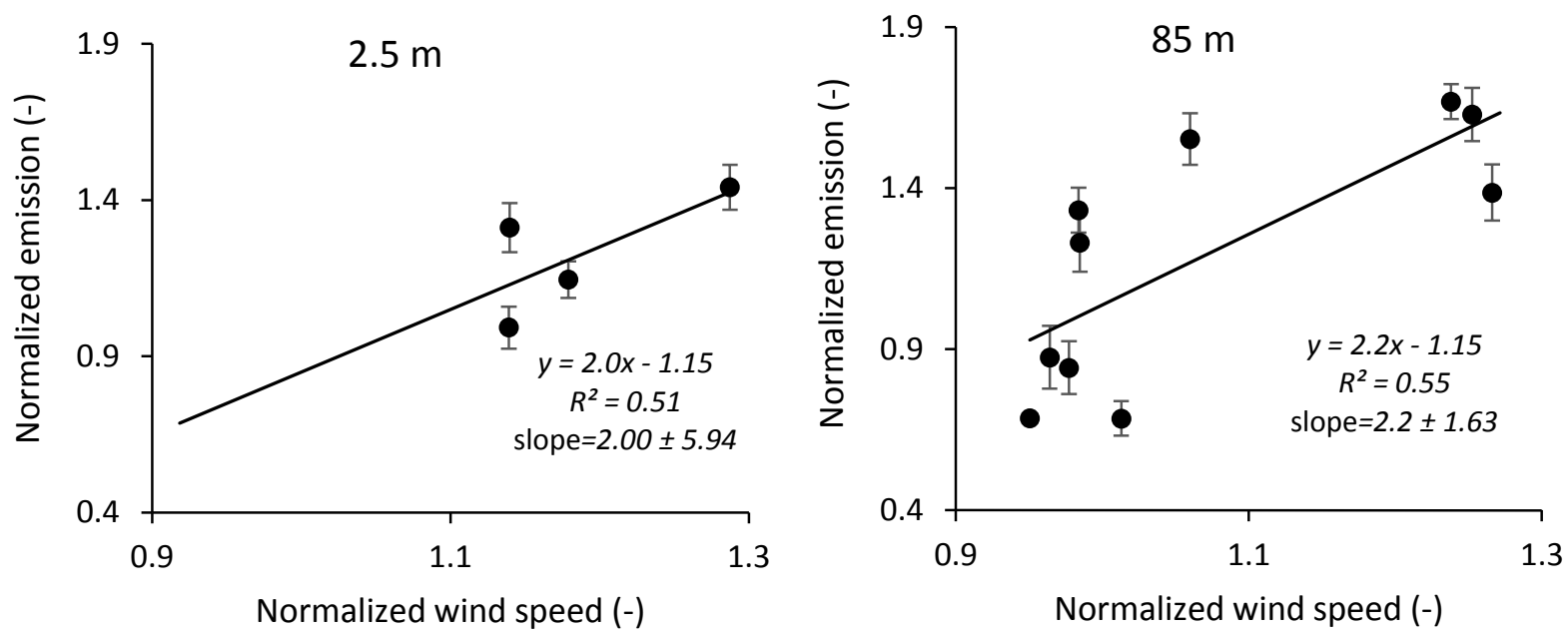

834

835 Figure 11. Normalized emissions calculated with TDM using 1-min field data at 2.5 and $85 \mathrm{~m}$

836 AGL at measurement location in Figure 1. Emissions plotted versus normalized wind speed on 837 landfill surface with data filtering: $R^{2}$ and second derivative of wind velocity criteria. 